\title{
EXTRACELLULAR L-GLUTAMINASE PRODUCTION BY MARINE BREVUNDIMONAS DIMINUTA MTCC 8486
}

\author{
Jayabalan R. ${ }^{1}$, Jeeva S. ${ }^{2}$ Sasikumar A.P. ${ }^{3}$, Inbakandan D. ${ }^{4}$, Swaminathan $K^{5}$, Yun S.E. ${ }^{6}$ \\ 1,2,5 Microbial Biotechnology Division, Department of Biotechnology, \\ Bharathiar University, Coimbatore, Tamilnadu, India. \\ ${ }^{3}$ Department of Biotechnology, St. Joseph's College, Tiruchirappalli, Tamilnadu, India. \\ ${ }^{4}$ Centre for Ocean Research, NIOT-SU Collaborative Research Centre, \\ Sathyabama University, Chennai, Tamil Nadu, India. \\ ${ }^{1,6}$ Department of Food Science and Technology, Institute of Agricultural \\ Science and Technology, Chonbuk National University, Jeonju 561-756, Republic of Korea. \\ E-mail: ${ }^{1}$ rasujayabalan@gmail.com
}

\begin{abstract}
Maximal L-glutaminase enzyme production by Brevundimonas diminuta MTCC $8486(48.4 \mathrm{U} / \mathrm{ml})$ occurred at pH $6.0,30^{\circ} \mathrm{C}$ in a sea water based medium supplemented with L-glutamine $(1 \%$, w/v), D-glucose $(1.5 \%$, w/v), peptone $(1 \%, w / v)$, and potassium dihydrogen phosphate $(1 \%, w / v)$ after $28 \mathrm{~h}$ of incubation and molecular weight of purified enzyme was $140 \mathrm{kDa}$.
\end{abstract}

Keywords : L-Glutaminase, Brevundimonas diminuta, marine bacteria

\section{INTRODUCTION}

L-Glutaminase (L-glutamine amidohydrolase EC 3.5.1.2.) is the enzyme deamidating L-glutamine to L-glutamic acid and ammonia. Glutaminase is ubiquitous in microorganisms and it plays a major role in the cellular metabolism of both prokaryotes and eukaryotes. In general, glutaminases from Escherichia coli, Pseudomonas spp., Rhizobium etli, Micrococcus luteus K-3, Bacillus spp., Clostridium welchii, Vibrio costicola, Zygosaccharomyces rouxii and Aspergillus oryzae have been isolated and well studied. In recent years glutaminase has attracted much attention with respect to proposed applications in food industries and pharmaceutical industries (Yokotsuka, 1985; Sabu, 2003). The activity of glutaminase, which is responsible for the synthesis of glutamic acid, makes it an important additive during soy sauce fermentation. Attempts to increase the glutamate content of soysuace using a salt tolerant and thermo tolerant glutaminases have drawn much attention (Nandakumar et al., 2003). Commercial importance demands not only the search for new and better yielding microbial strains, but also economically viable bioprocesses for its large scale production. Brevundimonas diminuta is a non-lactose-fermenting environmental Gram-negative bacilli previously assigned to the genus Pseudomonas. Previous reports state that B. diminuta TPU 5720 produces an amidase acting L-stereoselectively on phenylalaninamide (Komeda et al., 2006). It has been identified that approximately 60 microbial species could produce L-glutaminase (Nandakumar et al., 2003). Until now there are no reports available for the presence of L-glutaminase from B. diminuta. Since the enzymes from marine microorganisms play an important role in both pharmaceutical and food industries, the present study aimed to produce L-glutaminase from marine bacterium, B. diminuta MTCC 8486. The study also included process optimization for production of L-glutaminase, enzyme purification and molecular weight determination.

\section{MATERIALS AND METHODS}

A. Isolation and identification of $B$. diminuta

The bacterium used in the present study $B$. diminuta was isolated from the sea water collected from the coastal area of Arabian sea, Trivandrum, Kerala, India. The culture was maintained at ZoBell's agar slants (peptone $5 \mathrm{~g}$, yeast extract $1 \mathrm{~g}$, FePO4 4H2O $0.01 \mathrm{~g}$, agar $15 \mathrm{~g}$, aged seawater $750 \mathrm{ml}$, distilled water $250 \mathrm{ml}, \mathrm{pH} \mathrm{7.2)}$ and subcultured every month (Park et al., 2002). B. diminuta strain was identified at Microbial Type Culture Collection (MTCC), Chandigarh, India and it was deposited in MTCC and assigned as B. diminuta MTCC 8486. 


\section{B. Inoculum Preparation}

Inoculum prepared by growing the cells in marine broth $(100 \mathrm{ml}$, composition as in Zobell's agar, but without agar) for $24 \mathrm{~h}$ at $30^{\circ} \mathrm{C}$. The cells were pelleted by centrifugation at $15,000 \mathrm{rpm}$ for $10 \mathrm{~min}$. Pelleted cells were washed twice and resuspended in sterile saline and was used to inoculate the marine broth (Prabhu and Chandrasekaran, 1997).

\section{Effect of process parameters on production of L-glutaminase}

Marine broth $(100 \mathrm{ml})$ was taken as a basal medium in $250 \mathrm{ml}$ Erlenmeyer flask (shaken at 100 rpm) and the process parameters under study were varied. After optimization of each parameter, it was included in the next step at its optimal level. The parameters optimized were incubation time, initial $\mathrm{pH}$ of the medium (5-10), incubation temperature $\left(20-45^{\circ} \mathrm{C}\right.$ additional sodium chloride concentration (0-4\%), additional carbon sources (glucose, fructose, sucrose, maltose, mannitol and sorbitol at $1 \%$, w/v), additional nitrogen sources (peptone, yeast extract, beef extract, malt extract) additional inorganic salts (ammonium sulphate, ammonium nitrate, calcium nitrate, potassium dihydrogen phosphate at $1 \%, w / v$ ) and different amino acids (L-glutamine, L-glutamic acid, L-asparagine, arginine, methionine, proline and lysine at $1 \%$, w/v). Glutaminase was assayed according to Imada et al. (1973). Enzyme and substrate blanks were used as controls. One unit of L-glutaminase activity was defined as the amount of enzyme that liberated $1 \mu \mathrm{mol}$ of ammonia under optimal assay conditions.

\section{Purification and molecular weight determination of L-glutaminase}

Enzyme isolation and purification was conducted at $0-7^{\circ} \mathrm{C}$. The $\mathrm{pH}$ of the enzyme-containing cell extract was lowered to 6.5 by dropwise addition of phosphoric acid. Approximately $100 \mathrm{ml}$ of supernatant fluid which contained about $4.47 \mathrm{~g}$ of protein and 560 $U$ of L-glutaminase activity were applied to CM-Cellulose column (PHARMACIA FINE CHEMICALS) $(5 \times 80 \mathrm{~cm})$ which had been equilibrated with $0.04 \mathrm{M}$ sodium phosphate buffer, $\mathrm{pH}$ 6.5. The enzyme was eluted with $3 \mathrm{~L}$ liner gradient of 0 to $1 \mathrm{M} \mathrm{NaCl}$ in 0.04 $\mathrm{M}$ sodium phosphate buffer, $\mathrm{pH} 6.5$, at a flow rate of about $10 \mathrm{ml}$ per hour. Fractions of $1 \mathrm{ml}$ were collected and assayed for L-glutaminase activity. Glutaminase was eluted from the CM-cellulose column at between
0.15 to $0.25 \mathrm{M} \mathrm{NaCl}$ concentration in a relatively small volume. The active fractions were combined and the $\mathrm{pH}$ of the pool was adjusted to 7.2 with sodium hydroxide. Solid ammonium sulfate $(60 \%)$ was added slowly to the enzyme solution while maintaining $\mathrm{pH} 7.2$ by dropwise addition of ammonium hydroxide. After 30 $\min$ at $4^{\circ} \mathrm{C}$ the precipitate was removed by centrifugation and suspended in $0.01 \mathrm{M}$ sodium phosphate buffer, $\mathrm{pH}$ 7.2. The precipitate was dialyzed against the suspending buffer. The dialyzed enzyme solution $(12.6 \mathrm{ml})$ which contained about $7.3 \mathrm{mg}$ of protein and $160.02 \mathrm{U}$ of L-glutaminase activity was adjusted to $\mathrm{pH} 8.0$ with dilute $\mathrm{NaOH}$ and applied to a Sephadex column (G-200) (PHARMACIA FINE CHEMICALS) which has been equilibrated with $0.01 \mathrm{M}$ sodium phosphate buffer, $\mathrm{pH}$ 8.0. The column was eluted with $0.01 \mathrm{M}$ sodium phosphate buffer, $\mathrm{pH} 8.0$, at a flow rate of $0.5 \mathrm{ml} /$ minute (Roberts et al., 1972). The glutaminase pool of fractions which appeared at the front was adjusted to $\mathrm{pH} 7.2$ with dilute $\mathrm{HCl}$. Protein concentration was analyzed by the method of Lowry et al. (1951). Bovine serum $(1 \mathrm{mg} / \mathrm{ml})$ was used as the standard. Molecular weight of purified L-glutaminase was determined by SDS-polyacrylamide gel electrophoresis with appropriate protein markers (Laemmli, 1971).

\section{RESULTS AND DISCUSSION}

Extracellular L-glutaminase production by $B$. diminuta MTCC 8486 grown in shake flasks was observed in the present study. $B$. diminuta produced less L-glutaminase enzyme $(18 \mathrm{U} / \mathrm{ml})$ in nutrient broth compared to marine broth $(22 \mathrm{U} / \mathrm{ml})$ under same conditions after $24 \mathrm{~h}$ incubation period at $30^{\circ} \mathrm{C}$ (Data not shown). Hence, marine broth was selected as a basal medium to optimizing the process parameters for the production of L-glutaminase. From the Fig. 1 it is clear that $B$. diminuta produces maximum L-glutaminase at $28 \mathrm{~h}$ of incubation. Data presented in the Fig. 2 clearly indicated the influence of initial $\mathrm{pH}$ of the medium on L-glutaminase production by $B$. diminuta. The optimum pH was observed at pH $6.0(26.8 \mathrm{U} / \mathrm{ml})$. Enzyme production increased along with increase in $\mathrm{pH}$ from $12.4 \mathrm{U} / \mathrm{ml}$ at $\mathrm{pH} 4.0$ to a maximum of $26.8 \mathrm{U} / \mathrm{ml}$ at $\mathrm{pH}$ 6.0. Any further increase in the initial $\mathrm{pH}$ resulted in the reduction of enzyme production. Most of the extracellular enzymes are produced at higher levels at a growth $\mathrm{pH}$ that is near to the optimal $\mathrm{pH}$ required for the maximal enzyme activity (Tigue et al., 1994). 
Table 1. Effect of additives on L-glutaminase production by $B$. diminuta MTCC 8486

\begin{tabular}{|l|c|}
\hline \multicolumn{1}{|c|}{$\begin{array}{c}\text { Additives } \\
\text { (1\%, w/v) }\end{array}$} & $\begin{array}{c}\text { L-Glutaminase } \\
\text { activity }\left(\mathbf{U ~ m l}^{-1}\right)\end{array}$ \\
\hline Carbon sources & $33.5 \pm 1.0$ \\
Control & $35.1 \pm 0.3$ \\
Glucose & $34.0 \pm 0.3$ \\
Fructose & $33.8 \pm 0.2$ \\
Sucrose & $34.1 \pm 0.1$ \\
Sorbitol & $34.3 \pm 0.5$ \\
Mannitol & $34.4 \pm 0.4$ \\
Maltose & \\
Organic nitrogen sources & $38.2 \pm 0.3$ \\
Control & $42.6 \pm 0.4$ \\
Peptone & $36.2 \pm 0.6$ \\
Yeas extract & $38.6 \pm 0.2$ \\
Beef extract & $38.1 \pm 0.4$ \\
Malt extract & \\
Inorganic salt sources & $42.6 \pm 0.4$ \\
Control & $40.2 \pm 0.4$ \\
Ammonium sulphate & $41.2 \pm 0.5$ \\
Sodium nitrate & $39.4 \pm 0.8$ \\
Calcium nitrate & $44.3 \pm 0.5$ \\
Potassium dihydrogen & \\
phosphate & \\
Ammonia acids & $44.3 \pm 0.5$ \\
Control & $48.4 \pm 0.4$ \\
L-Glutamine & $42.8 \pm 0.6$ \\
Glutamic acid & $37.2 \pm 0.5$ \\
Asparagine & $26.0 \pm 0.8$ \\
Arginine & $28.0 \pm 0.6$ \\
Methionine & $15.6 \pm 0.4$ \\
Proline & $18.2 \pm 0.6$ \\
Lysine & \\
\hline & \\
\hline
\end{tabular}

Values are mean \pm standard deviation; $n=3$

samples. Optimized parameters are included in next step.
Incubation at $30^{\circ} \mathrm{C}$, at $\mathrm{pH} 6.0$ (optimized), slightly enhanced the enzyme production $(27.2 \mathrm{U} / \mathrm{ml})$ compared to other temperatures (Fig. 3). No growth of $B$. diminuta was observed at 40 and $45^{\circ} \mathrm{C}$ suggested that the bacterium is a mesophile (data not shown). Nevertheless, a considerable level of enzyme production could be obtained at other $\mathrm{pH}$ and temperatures. Prabhu and Chandrasekaran (1997) obtained maximal L-glutaminase yield by marine Vibrio costicola in solid state fermentation at $35^{\circ} \mathrm{C}$ and $\mathrm{pH}$ 7.0, after $24 \mathrm{~h}$. Maximal extracellular L-glutaminase titres by Zygosaccharomyces rouxii were produced when solid state fermentation was carried out at $30^{\circ} \mathrm{C}$ incubation temperature and $48 \mathrm{~h}$ of incubation period (Kashyap et al., 2002). These factors are largely characteristic of the organism and vary for each species (Chandrasekaran et al., 1991).

The salt dependence of glutaminase was determined by adding $0-5 \% \quad(\mathrm{w} / \mathrm{v}) \mathrm{NaCl}$ to the production medium. Glutaminase activity was increased from 27.2 to $33.5 \mathrm{U} / \mathrm{ml}$ at $2.5 \% \mathrm{NaCl}$. Addition of $\mathrm{NaCl}$ above $2.5 \%$ led to a decline in the enzyme production. (Fig. 4). Furthermore, in presence of $4 \%$ salt the enzyme activity retains still $87.5 \%$ compared to the reaction with $2.5 \% \mathrm{NaCl}$. No growth of $B$. diminuta was observed in the medium with above $4 \% \mathrm{NaCl}$ (Data not shown). This indicates that the bacterium is not halophilic, but could be halotolerant and a natural commensal organism of the marine environment.

Results on the effect of supplementation of production medium with different carbon sources such as glucose, sucrose, maltose, sorbitol, fructose and mannitol on enzyme production are shown in the Table 1. Incorporation of additional carbon sources enhanced enzyme yield from $33.5 \mathrm{U} / \mathrm{ml}$ to $35.1 \mathrm{U} / \mathrm{ml}$. Among the carbon sources tested D-glucose (1\%) promoted maximal yield $(35.1 \mathrm{U} / \mathrm{ml})$ compared to others. Interestingly, supplementation of all the carbon sources

Table 2. Purification of $B$. diminuta MTCC 8486 L-glutaminase

\begin{tabular}{|lccccc|}
\hline \multicolumn{1}{|c}{ Fraction } & $\begin{array}{c}\text { Volume } \\
(\mathrm{ml})\end{array}$ & $\begin{array}{c}\text { Total Protein } \\
\left(\mathrm{mg} \mathrm{ml}^{-1}\right)\end{array}$ & $\begin{array}{c}\text { Total activity } \\
(\mathbf{U})\end{array}$ & $\begin{array}{c}\text { Specific activity } \\
\left(\mathrm{U} \mathrm{mg}^{-1}\right)\end{array}$ & $\begin{array}{c}\text { Purification } \\
\text { factor }\end{array}$ \\
\hline Cell suspension & 100 & 447 & 560 & 1.25 & 1 \\
CM-cellulose & 16 & 93.76 & 163.2 & 1.74 & 1.39 \\
$60 \%\left(\mathrm{NH}_{4}\right)_{2} \mathrm{SO}_{4}$ & 12.6 & 7.3 & 160.02 & 21.92 & 17.53 \\
Sephadex-G-200 & 1.4 & 0.36 & 156.4 & 60.15 & 48.12 \\
\hline
\end{tabular}




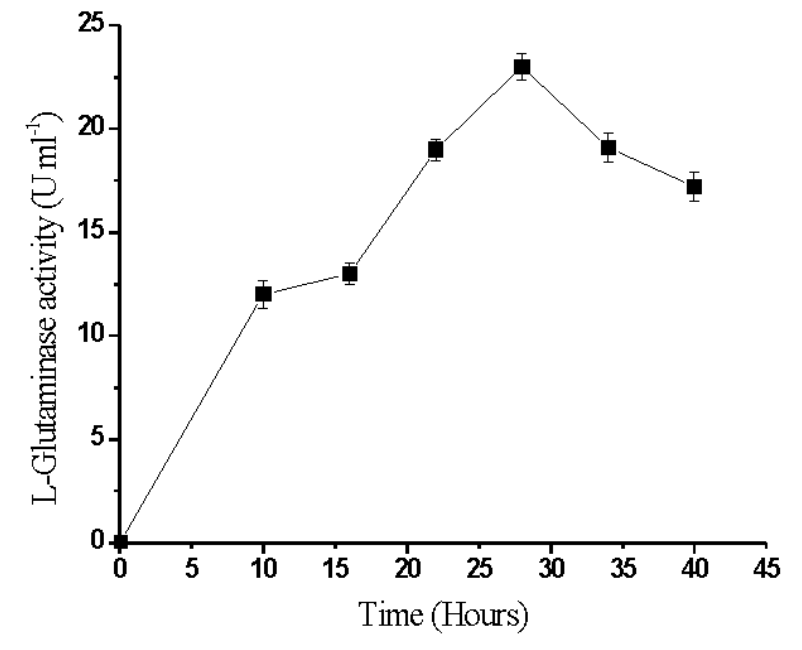

Fig. 1. Effect of incubation time on L-glutaminase production by $B$. diminuta MTCC 8486

Values are mean \pm standard deviation;

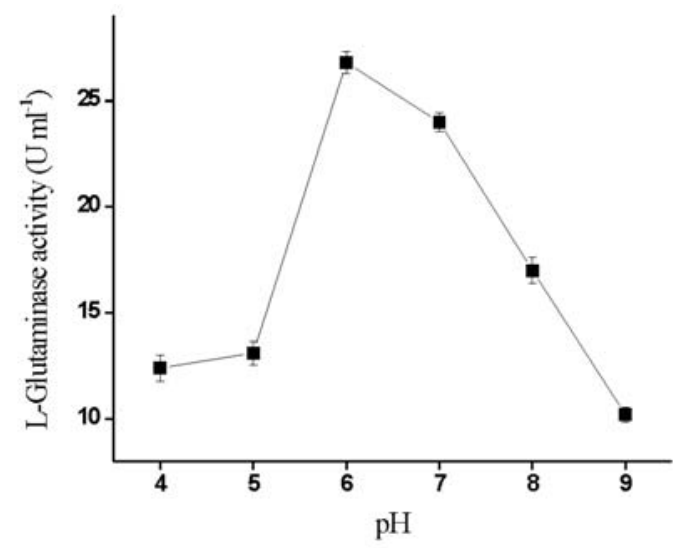

Fig. 2. Effect of initial medium pH on L-glutaminase production by $B$. diminuta MTCC 8486

Values are mean \pm standard deviation;

$$
\mathrm{n}=3 \text { samples. }
$$

to the production medium enhances enzyme production by the marine bacteria. Sabu et al. (2000) reported the results on optimization of process parameters for the production of L-glutaminase by the marine fungus, Beauveria bassiana under solid state fermentation on an inert substrate. They found that among various carbon sources tested D-glucose at $0.5 \%$, w/v almost doubled the glutaminase yield compared with others. Maltose $(1 \%$, w/v) was found to enhance L-glutaminase production by $V$. costicola under solid state fermentation (Prabhu and Chandrasekaran, 1997). The enhanced

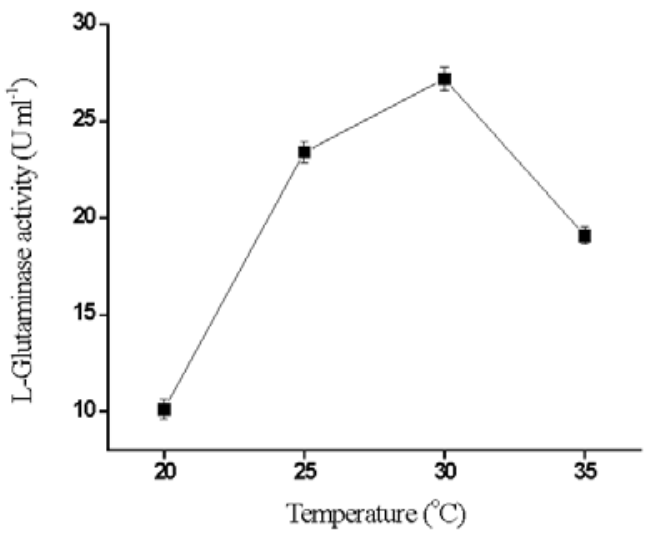

Fig. 3. Effect of incubation temperature on L-glutaminase production by $B$. diminuta MTCC 8486

Values are mean \pm standard deviation; $\mathrm{n}=3$ samples.

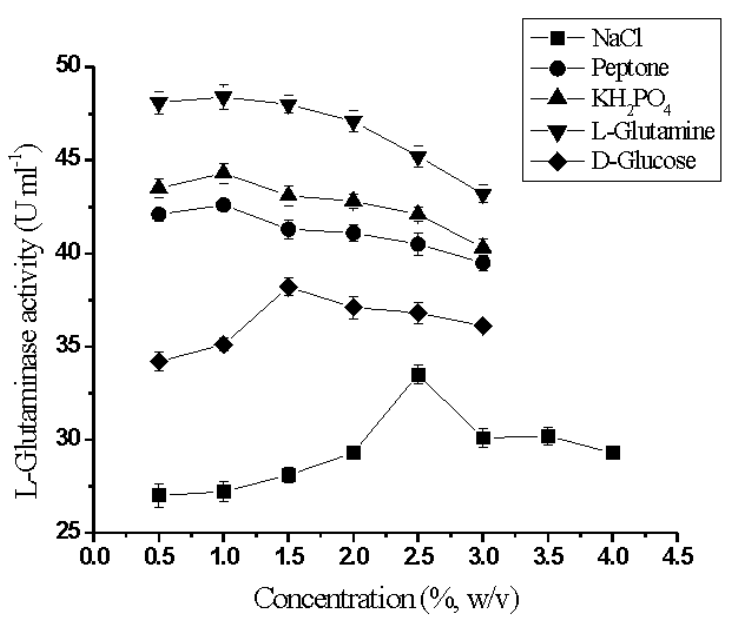

Fig. 4. Effect of additional $\mathrm{NaCl}$, lactose, peptone, potassium dihydrogen phosphate and glutamine concentration on on L-glutaminase production by B. . diminuta MTCC 8486 diminuta MTCC 8486

Values are mean \pm standard deviation; $\mathrm{n}=3$ samples.

production of L-glutaminase by incorporation of carbon sources may be attributed to the positive influence of additional carbon sources along with glutamine on enhanced biosynthesis. Further studies were carried out for optimizing the concentration of glucose, which showed that $1.5 \%(\mathrm{w} / \mathrm{v})$ glucose was optimal for maximum glutaminase (38.2 U/ml) (Fig. 4).

The results on the effect of addition of organic nitrogen sources, namely peptone, yeast extract, beef extract and malt extract on enzyme production after 


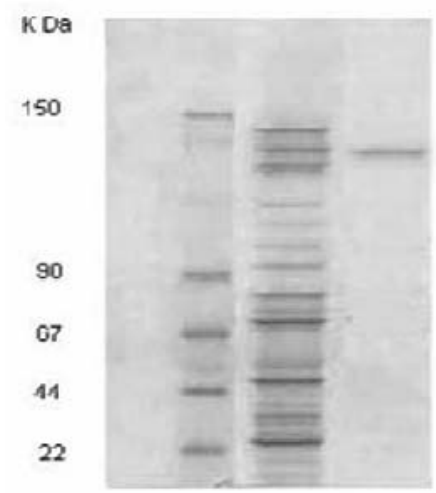

Fig. 5. SDS-PAGE of purified glutaminase from $B$. diminuta MTCC 8486.

Lanes: 1-Molecular markers, 2-crude enzyme, 3-purified glutaminase

$28 \mathrm{~h}$ when they were incorporated in the medium at $1 \%$, w/v level revealed that peptone enhanced the enzyme yield from 38.2 to $42.6 \mathrm{U} / \mathrm{ml}$ (Table 1). Further studies on peptone showed that $1 \%$ is the optimal concentration for the production of L-glutaminase by $B$. diminuta (Fig. 4). Nitrogen can be an important limited factor in the microbial production of enzymes (Chandrasekaran et al., 1991). It has also been reported that addition of yeast extract or tryptone to the growth medium resulted in significantly lower levels of enzyme activity (Roberts et al., 1972).

Among the inorganic salt sources tested, only potassium dihydrogen phosphate was found to enhance the L-glutaminase production $(44.3 \mathrm{U} / \mathrm{ml})$. Ammonium sulphate, sodium nitrate and calcium nitrate were found to decrease the enzyme production at $1 \%, w / v$ concentration (Table 1). Further studies on potassium dihydrogen phophate concentration revealed that $1 \%$, $\mathrm{w} / \mathrm{v}$ is the optimal level for maximum enzyme yield (Fig. 4). This result emphasise the critical role of phosphate in the enhanced secretion of glutaminase. Among the different amino acids tested, L-glutamine was observed to enhance L-glutaminase synthesis $(48.4 \mathrm{U} / \mathrm{ml})$ (Table 1). This observation suggests that L-glutamine act as an inducer for the production of extracellular L-glutaminase enzyme. L-Glutaminase production occurred even in the absence of L-glutamine as well as any additional amino acid in the seawater medium. This particular observation suggests that Brevundimonas diminuta could produce extracellular L-glutaminase even in the absence of an enzyme inducer, when sea water was used as a medium. A detailed study on the molecular mechanism involved in the role of seawater components in the biosynthesis of L-glutaminase would produce information on the biology of these organisms in natural environment alongside designing an economically viable fermentation media. The effect of glutamine concentration on production was evaluated in detail, which revealed that $1 \%$ glutamine was the optimal concentration for the maximal enzyme production (Fig. 4).

A summary of purification procedure was given in Table 2. The enzyme was purified 48.12 fold. The final specific activity was 60.15. The enzyme was judged homogeneous by SDS-gel electrophoresis and the molecular weight of purified glutaminase was found to be $140 \mathrm{kDa}$ (Fig. 5). L-glutaminase with molecular mass of 132 and $137 \mathrm{kDa}$ was reported from Acinetobacter glutaminasificans and Pseudomonas aeruginosa respectively (Nandakumar et al., 2003).

\section{CONCLUSION}

In conclusion, the results of the present study indicate scope for exploring marine bacterium, $B$. diminuta as a source for L-glutaminase, an enzyme that has gained industrial and pharmaceutical significance recently. Secondly marine bacteria grown in shake flasks can produce extracellular enzyme. Thirdly seawater could provide the base for fermentation media for L-glutaminase production by marine bacteria.

\section{ACKNOWLEDGEMENTS}

Financial support from the Tamil Nadu State Council for Science and Technology, Tamil Nadu, India [Grant No.TNSCST/STU PRJ/RJ/2005-06] is thankfully acknowledged. The research was also partly supported by the Research Center for Industrial Development of Biofood Materials in the Chonbuk National University (Jeonju, Korea).

\section{REFERENCES}

[1] Chandrasekaran, M., Lakshmanaperumalsamy, P., Chandramohan, D. 1991. Combined effect of environmental factors on spoilage bacteria. Fish Tech (India), 28, 146-153.

[2] Imada, A., Igarasi, S., Nakahama, K., Isono, M. 1973. Asparginase and glutaminase activities of microorganisms. J Gen Microbiol, 76, 85-99.

[3] Kashyap, P., Sabu, A., Pandey, A., Szakacs, G., Soccol, R.C. 2002. Extracellular L-glutaminase 
production by Zygosaccharomyces rouxii under solid state fermentation. Process Biochem, 38, 307-312.

[4] Komeda, H., Hariyama, N., Asano, Y. 2006. L-Stereoselective amino acid amidase with broad substrate specificity from Brevundimonas diminuta: characterization of a new member of the leucine aminopeptidase family. Appl Microbiol Biotechnol, 70, 412-421.

[5] Laemmli, U.K. 1971. Cleavage of structural proteins during the assembly of the head of bacterial phage T4. Nature. 227, 680-685.

[6] Lowry, O.H., Rosebrough, N., Farr, A.L., Ronadall, R.L. 1951, Protein measurement with the folin phenol reagent. J Biol Chem, 193, 265-273.

[7] Middelhoven, W.J., Doesburg, W.V. 2007. Utilization of hexamethylenetetramine (urotropine) by bacteria and yeasts. Antonie Van Leeuwenhoek, 91, 191-196.

[8] Nandakumar, R., Yoshimune, K., Wakayama, M., Moriguchi, M. 2003. Microbial glutaminase: biochemistry, molecular approaches and applications in the food industry. J Mol Cat B: Enzymatic, 23, 87-100.

[9] Park, S.H., Kwon, K.K., Lee, D.S., Lee, H.K. 2002. Morphological diversity of marine microorganisms on different isolation media. J Microbiol, 40, 161-165.

[10] Prabhu, G.H., Chandrasekaran, M. 1997. Impact of process paramaeters on L-Gluaminase production by marine Vibrio costicola in solid state fermentation using polystyrene as an inert support. Process Biochem, 32, 285-289.

[11] Roberts, J., Holcenberg, J.S., Dolowy, W.C. 1972. Isolation, crystallization and properties of
Achromobacteraceae Glutaminase-Asparaginase with antitumor activity. J Biol Chem, 247, 84-92.

[12] Sabu, A., 2003. Sources, properties and applications of microbial therapeutic enzymes. Indian J Biotechnol, 2, 334-341.

[13] Sabu, A., Keerthi, T.R., Rajeev Kumar, S., Chandrasekaran, M. 2000. L-Glutaminase production by marine Beauveria sp. under solid state fermentation. Process Biochem, 35, 705-710.

[14] Tigue, M.A., Kelly, C.T., Fogarty, W.M., Doyle, E.M. 1994. Production studies on the alkalophilic amylase of three alkalophilic Bacillus sp. Biotechnol Lett, 16, 569-574.

[15] Yokotsuka, Y. 1985. Fermented protein foods in the Orient, with emphasis on shoy and miso in Japan, London, Ed. Wood B. J. B., Elsevier Applied Science, 197-247.

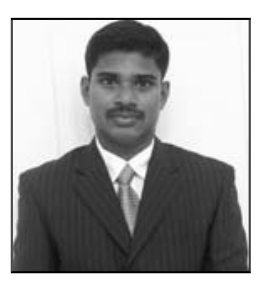

Dr. R. Jayabalan completed his doctoral degree from Bharathiar University, Coimbatore, Tamil Nadu, India and currently working as Post Doctoral fellow in Department of Food Science and Technology, Chonbuk National University, Jeonju, Republic of Korea. He was working as lecturer in Biotechnology Department, Sathyabama University, Chennai, Tamil Nadu, India. He is interested in microbial biotransformation and fermentation processes and actively involved in teaching and research. 